\title{
Diagnostic and Therapeutic Challenges in Pediatric Eosinophilic Esophagitis: Past, Present and Future
}

\author{
Sandeep K. Gupta \\ Clinical Pediatrics and Clinical Medicine, Riley Hospital for Children, Indiana University School of Medicine, \\ Indianapolis, Ind., USA
}

\section{Key Words}

Eosinophilic esophagitis · Diagnostic tests · Therapy ·

Future directions

\begin{abstract}
In this paper, we will discuss the nuances of pediatric eosinophilic esophagitis based on symptoms, diagnostics and therapy. The diagnostics will include endoscopy, histology and anesthesia. Therapeutics will include the diet, drugs and 'distress'. Future directions in terms of clinical presentation and diagnostics will be discussed and important issues such as repeated exposure to anesthetic agents and effects of therapy on growth and psychological distress will be listed.
\end{abstract}

(c) 2014 S. Karger AG, Basel

\section{Symptoms}

Symptoms in pediatric eosinophilic esophagitis (EoE) vary by age and some of the reasons for this variation are due to the limited ability of children to express symptoms and because the disease phenotype in children varies, i.e. inflammatory versus fibrotic $[1,2]$. In addition, children may become adept at employing coping mechanisms to help overcome the disease and its associated symptoms. In children the disease is not always fibrotic but starts off as an inflammatory phenotype. As such, dysphagia and food impactions are less commonly seen in pediatric patients, but do increase with age into the teenager years. In contrast, dysphagia is a near-universal symptom in adult patients with EoE. The coping mechanisms of EoE seen in children include texture avoidance, excessive chewing of food, cutting food into tiny small bites, taking forever to finish a meal, and excessive use of liquids to push the food down. Symptoms can be age dependent, and in the toddler years we often see feeding disorder, refusal to feed or failure to thrive as a presenting symptom, whereas vomiting is more common in school-age children as is nonspecific abdominal pain. Dysphagia and food impactions become more common in teenage years [3].

I suspect in the coming years we will continue to see symptomatology that is age dependent in pediatric EoE, but it appears there is an increasing number of children who are preteens or younger presenting with food impactions [pers. obs.]. I anticipate we will be using more screening symptom scoring tools such as the Pediatric Eosinophilic Esophagitis Activity Index (pedEEsAI), Pediatric Eosinophilic Esophagitis Symptom Score (PEESS) and Dysphagia Symptom Questionnaire (DSQ) $[4,5]$ in the near future as these receive in-depth study, become further validated and undergo scientific critique for publication. Recent data shows that there are increasing hospitalizations from EoE as in the study by Erwin et al. [6] from 2012. This finding together with increasing presentation of EoE patients to the emergency room with food impactions provide opportunities to educate other nongastroenterologist providers such as emergency room physicians, hospitalists and general pediatricians on EoE.

\section{KARGER}

E-Mail karger@karger.com

www.karger.com/ddi
(C) 2014 S. Karger AG, Basel

0257-2753/14/0322-0107\$39.50/0
Prof. Sandeep K. Gupta, MD

Clinical Pediatrics and Clinical Medicine

Riley Hospital for Children, Indiana University School of Medicine

705 Riley Hospital Dr., Indianapolis, IN 46202 (USA)

E-Mail sgupta@iu.edu 


\section{Diagnostics}

While findings such as linear furrows, white specks and rings are commonly seen during endoscopic evaluation of a patient with EoE, in up to a third or even half of the patients with EoE the esophageal mucosa can appear normal or unremarkable [7-9]. As such, in pediatrics one needs to have a high index of suspicion and biopsy the esophageal mucosa for histological examination even if it appears endoscopically unremarkable or normal. Often the histology in pediatric EoE is that which is seen in adults. It includes eosinophilic infiltration and fibrotic changes such as lamina propria fibrosis and basal cell hyperplasia, though occasionally one may note eosinophilic infiltration without epithelial changes or fibrosis. It is unclear if this group of patients is the same as classic EoE or represents a different subgroup of the disease. We also need to know what to make of children with 6-14 eosinophils per high-power field and whether these are EoE in evolution or another disease category. Some of these children in previous studies responded to proton pump inhibitor therapy while others did not [10]. Children with EoE often undergo repeated endoscopies and there are concerns that exposure to general anesthesia especially in the young child may negatively affect their development. In fact, the US Food and Drug Administration is involved in an initiative called SmartTots (Strategies for Mitigating Anesthesia-Related Neurotoxicity in Tots) that aims to study the effects of anesthesia on childhood development [11].

Moving forward in diagnostics, I suspect we will increasingly subclassify the phenotypes as inflammatory, fibrotic or mixed. We will be paying more attention to (1) eosinophil activation beyond just the raw numbers of eosinophils, (2) esophageal function test, i.e. how does fibrosis affect esophageal function, and (3) stain for profibrotic markers such as periostin within the epithelium as the lamina propria is not always available for analysis [12]. The esophageal string test is an exciting and promising innovation [13]. We need to continue studying the risk of general anesthesia in children.

\section{Therapy}

In terms of therapy, there have been two significant developments in the treatment of this disease: swallowed corticosteroids and empiric food elimination diets. While the four-food elimination diet is still under study, the empiric dietary modifications such as the six-food elimina- tion diet have been studied and are relatively easy to implement in infants and somewhat easy to implement in toddlers because the parents are still in control of the child's diet. It can be practical to do for the school-age child if the child agrees to do it. With teenagers, this diet becomes more difficult because of their lifestyle including school, part-time jobs, social activities, sports, etc. If a teenager's family wishes for dietary modifications, I would suggest an in-depth and one-on-one interview with the teenager to inquire into his/her preference and decisions regarding healthcare and how he/she would like to treat his/her disease. Swallowed corticosteroids do tend to work, but it is unclear whether they carry any long-term side effects or not. A recent study [14] published in 2012 on the use of inhaled budesonide for asthma showed a decrease in height velocity that was sustained over the next several years with use of inhaled corticosteroids. It is unclear if the same would apply to EoE, but children with EoE who receive topical corticosteroid therapy should be monitored for linear growth especially since EoE patients may also have altered metabolism of budesonide [15].

The diagnosis of this chronic condition often results in distress in the family $[16,17]$. This is especially so in a truly asymptomatic (or minimally symptomatic child with some coping mechanisms) child incidentally diagnosed to have EoE when being seen for another reason such as rectal bleeding or polyp disorders. Furthermore, the family often feels threatened by the disease and are worried about the child in instances where they may be traveling away from home for a summer camp or a school trip. Studies show that families with children with EoE report higher stress, psychological distress and anxiety.

In summary, children with EoE are not mini-adults and symptomatology in children is age dependent and opens nontraditional venues of education for other providers. Newer diagnostic and symptom scores are anticipated to be used as we move forward. Therapy in children with EoE can have an impact on nutrition and linear growth, as well as result in family distress. All of these issues require special attention.

\section{Disclosure Statement}

Consultant for Abbott, QOL, Meritage and Receptos, and speaker for Nestlé. 


\section{References}

1 Lucendo AJ, Sánchez-Cazalilla M: Adult versus pediatric eosinophilic esophagitis: important differences and similarities for the clinician to understand. Expert Rev Clin Immunol 2012;8:733-745.

-2 Noel RJ, Putnam PE, Rothenberg ME: Eosinophilic esophagitis. N Engl J Med 200426;351: 940-941.

$>3$ El-Matary W, El-Hakim H, Popel J: Eosinophilic esophagitis in children needing emergency endoscopy for foreign body and food bolus impaction. Pediatr Emerg Care 2012; 28:611-613.

-4 Franciosi JP, Hommel KA, DeBrosse CW, Greenberg AB, Greenler AJ, Abonia JP, Rothenberg ME, Varni JW: Development of a validated patient-reported symptom metric for pediatric eosinophilic esophagitis: qualitative methods. BMC Gastroenterol 2011;11: 126.

5 Dellon ES, Irani AM, Hill MR, Hirano I: Development and field testing of a novel patientreported outcome measure of dysphagia in patients with eosinophilic esophagitis. Aliment Pharmacol Ther 2013;38:634-642.
6 Erwin EA,Hemming T, Kelleher KJ: A decade of hospital discharges related to eosinophilic esophagitis. J Pediatr Gastroenterol Nutr 2012;54:427-429.

7 Gupta SK, Fitzgerald JF, Chong SK, et al: Are vertical lines in distal esophageal mucosa a true manifestation of peptic esophagitis in children. Gastrointest Endosc 1995;41:338.

8 Lim JR, Gupta SK, Fitzgerald JF, Croffie JM, Pfefferkorn MD, Molleston JP, Corkins MR, Davis M, Steiner SJ: White specks in esophageal mucosa (WSEM): an endoscopic manifestation of non-reflux eosinophilic esophagitis (EE) in children. Gastrointest Endosc 2004;59:835-838.

-9 Liacouras CA, Spergel JM, Ruchelli E, Verma R, Mascarenhas M, Semeao E, Markowitz JE: Eosinophilic esophagitis: a 10-year experience in 381 children. Clin Gastroenterol Hepatol 2005;3:1198-1206.

10 Baxi, S, Gupta SK, Swigonski N, Fitzgerald JF: Clinical presentation of patients with eosinophilic inflammation of the esophagus. Gastrointest Endosc 2006;64:473-478.

$\checkmark 11$ Rappaport B, Mellon RD, Simone A, Woodcock J: Defining safe use of anesthesia in children. N Engl J Med 2011;364:1387-1390.

12 Davis M, Tuana F, Yao W, Kaplan M, Gupta SK: Biomarkers of tissue inflammation in eosinophilic esophagitis (EE). J Pediatr Gastroenterol Nutr 2007;45:E28.
13 Fillon SA, Harris JK, Wagner BD, Kelly CJ, Stevens MJ, Moore W, Fang R, Schroeder S, Masterson JC, Robertson CE, Pace NR, Ackerman SJ, Furuta GT: Novel device to sample the esophageal microbiome - the esophageal string test. PLoS One 2012;7:e42938.

14 Kelly HW, Sternberg AL, Lescher R, Fuhlbrigge AL, Williams $\mathrm{P}$, Zeiger, RS, Raissy $\mathrm{HH}$, Van Natta ML, Tonascia J, Strunk for the CAMP Research Group: Effect of inhaled glucocorticoids in childhood on adult height. $\mathrm{N}$ Engl J Med 2012;367:904-912.

15 Dilger K, Lopez-Lazaro L, Marx C, Bussmann C, Straumann A: Active eosinophilic esophagitis is associated with impaired elimination of budesonide by cytochrome P450 3A enzymes. Digestion 2013;87:110-117.

-16 Taft TH, Ballou S, Keefer L: Preliminary evaluation of maternal caregiver stress in pediatric eosinophilic gastrointestinal disorders. J Pediatr Psychol 2012;37:523-532.

17 Klinnert MD: Psychological impact of eosinophilic esophagitis on children and families. Immunol Allergy Clin North Am 2009;29: 99-107. 